\title{
Intervertebral disc heights and concavity index of the lumbar spine in young healthy adults
}

\author{
Mehmet Demir ${ }^{1}$, Emre Atay $^{2}$, Nurten Seringeç ${ }^{3}$, Atila Yoldaşs ${ }^{1}$ Mustafa Çiçek ${ }^{1}$, \\ Rodi Ertoğrul ${ }^{4}$, Bülent Güneri ${ }^{5}$ \\ ${ }^{1}$ Department of Anatomy, Faculty of Medicine, Kabramanmaraş Siitçii İmam University, Kabramanmaras, Turkey \\ ${ }^{2}$ School of Health, Niğde Ömer Halisdemir University, Niğde, Turkey \\ ${ }^{3}$ Department of Physiology, Faculty of Medicine, Kahramanmaras Sïţii Imam University, Kabramanmaras, Turkey \\ ${ }^{4}$ Department of Orthopedics and Traumatology, Kilis State Hospital, Kilis, Turkey \\ ${ }^{5}$ Department of Orthopedics and Traumatology, Faculty of Medicine, Kabramanmaraş Siitçii Imam University, Kabramanmaraş, Turkey
}

\begin{abstract}
Objectives: The aim of this study was to investigate lumbar intervertebral disc heights and concavity index of the lumbar spine, and the influence of age, gender, weight, height and body mass index (BMI) on these parameters.

Methods: The study was conducted on 150 health young subjects (age 18 to 27) without any disorder which affects the lumbar spine and the discs. Subjects underwent standard standing lateral lumbar radiography. Mann-Whitney U test and Spearman's correlation test were used for statistical analysis.

Results: Of the 150 subjects (age range, 18-27 years), 80 (53.3\%) were women and 70 (46.7\%) were men. Men presented higher lumbar disc values than women. In both genders, disc height increased from T12-L1 to L4-L5, and then decreased at L5-S1. The heights of all lumbar discs increased with age, weight, height and BMI in both genders. Women demonstrated a higher concavity index at L2, L3 and L4 vertebrae compared to men, whereas men showed a higher concavity index value at $L 5$ vertebra. The concavity index of T12, L1, L2, L3 and L4 vertebrae decreased with age.
\end{abstract}

Conclusion: Our results will serve as guidelines and references for further studies, radiologists and spinal surgeons.

Keywords: concavity index; intervertebral disc; lumbar vertebrae; radiography, spine

Anatomy 2018;12(1):33-37 @2018 Turkish Society of Anatomy and Clinical Anatomy (TSACA)

\section{Introduction}

The demands on the lumbar spine in daily, professional and recreational activities is very strong. Lumbar spine is supposed to be stable and bear high static and dynamic axial loads and also demonstrate flexibility to ensure a high degree of mobility of the entire spine. Junghanns ${ }^{[1]}$ defines the segment of movement as the smallest structural and functional unit of the lumbar spine. The intervertebral (IV) disc is a dynamic structure which lies between the vertebrae and consists of anulus fibrosus, nucleus pulposus and end plates. ${ }^{[2]}$ The IV disc is one of the largest avascular tissues in the body with no blood vessels, neurons and lymphatic structures. Discs are supplied by vessels in the subchondral bone adjacent to the hyaline cartilage of the end plate. Therefore, the discs show a slow and limited healing process after injury. Progressive and serious changes also occur with increasing age. ${ }^{[3,4]}$ The most common cause of low back or upper neck pain problems are degenerations that occur in the IV discs. The causes of these degenerations are fluid loss in nucleus pulposus, rupture of annulus fibrosus, weakening of the connections between the intervertebral foramen and loss of function. These alterations will reduce the ability to absorb forces and durability with advancing age. They also lead to a decrease in the disc height, and disc herniation or bulging over time. ${ }^{[5]}$ Biomechanical changes in the discs with aging also affect the height due to their location. ${ }^{[6]}$ Over the years, various diagnostic methods have been developed for early detection of these and similar degenerative changes to improve the treatment strategies. ${ }^{[3]}$ Computed tomogra- 
phy (CT), magnetic resonance imaging (MRI), ultrasonography (US) and radiography (X-ray) techniques are widely used for imaging and diagnosis of spinal disorders. ${ }^{[5]}$ Especially, radiography is the simplest and cost-effective method that can be applied even in primary health-care services. This is currently the most frequently used imaging technique to detect vertebral and discal disorders. ${ }^{[7,8]}$

In this study, we aimed to establish reference values for disc height and concavity index of lumbar vertebral bodies in healthy young Turkish population on radiographic examination, as well as to determine the influence of age, gender, weight, height and BMI on aforementioned values.

\section{Materials and Methods}

This study was conducted at Orthopedics and Traumatology Departments of Sütçü İmam University and Kilis State Hospital. X-ray images were selected from 180 healthy young adults (90 women, 90 men) without low back pain or hip disorders who underwent standardized standing lateral lumbar radiography for various reasons from the hospital archive database. The age of subjects ranged from 18 to 27 years old. In addition, the demographic data (sex, age, body weight, height, BMI) of each subject and the phone number was recorded. Subjects with spinal disorders such as Bechterew disease, Scheuermann's disease, scoliosis, spinal metastasis, spondylolisthesis, low back pain, osteoporosis, hip disorder and history of trauma were excluded. Of the 180 subjects assessed according to the protocol, 150 subjects ( 80 women, 70 men) were included; 21 subjects did not come for an interview about their clinical condition and the remaining patients matched one or more of the exclusion criteria. This study was approved by the Faculty of Medicine Clinical Research Ethics Committee of Kahramanmaraş Sütçü İmam University, and voluntary informed consent forms were obtained from the participants. The radiographic cassette was placed to right side of each participant in relaxed standing position, with joining their hands behind the neck.

$\mathrm{X}$-ray images were taken with the beam focused on the third lumbar vertebrae, with anode-film distance between 100 to $120 \mathrm{~cm}$. The height of the lumbar discs were measured according to the Leivseth et al. ${ }^{[9]}$ protocol, and the concavity index for each vertebra was calculated, dividing the central vertebral height with the anterior vertebral height (Figure 1) ${ }^{[10]} \mathrm{We}$ used Image J software (National Institute of Mental Health, Bethesda, Maryland, USA) to measure the disc height and concav-
Table 1

Demographic characteristics of the groups using Mann-Whitney $U$ test.

\begin{tabular}{lcccc}
\hline & $\begin{array}{c}\text { Male } \\
(\mathbf{n}=\mathbf{7 0})\end{array}$ & $\begin{array}{c}\text { Female } \\
(\mathbf{n}=\mathbf{8 0})\end{array}$ & $\begin{array}{c}\text { Total } \\
(\mathbf{n}=\mathbf{1 5 0 )}\end{array}$ & $\mathbf{p}$ \\
\hline Age (years) & $20.97 \pm 1.7$ & $20.73 \pm 1.87$ & $20.83 \pm 1.8$ & 0.192 \\
Weight $(\mathrm{kg})$ & $72.85 \pm 10.54$ & $55.97 \pm 6.95$ & $63.76 \pm 12.15$ & $\mathrm{p}<0.001$ * \\
Height $(\mathrm{cm})$ & $176.69 \pm 6.03$ & $162.81 \pm 4.94$ & $169.30 \pm 8.85$ & $\mathrm{p}<0.001$ * \\
BMl $\left(\mathrm{kg} / \mathrm{m}^{2}\right)$ & $23.29 \pm 2.79$ & $21.10 \pm 2.25$ & $23.30 \pm 2.73$ & $\mathrm{p}<0.001$ * \\
\hline
\end{tabular}

${ }^{*} p<0.001$

ity index of the lumbar spine on the digitized lateral radiographs.

Statistical analysis was performed using SPSS Version 16.0 (SPSS Inc., Chicago, IL, USA). The normal distribution of the data was assessed by Kolmogorov-Smirnov test and homogeneity of variance of the data was assessed by Levene's test. Mann-Whitney U test was used to compare the groups. Correlation between parameters was determined by Spearman's correlation test. $\mathrm{p}<0.05$ was accepted to be statistically significant. Data were presented as mean \pm SEM.

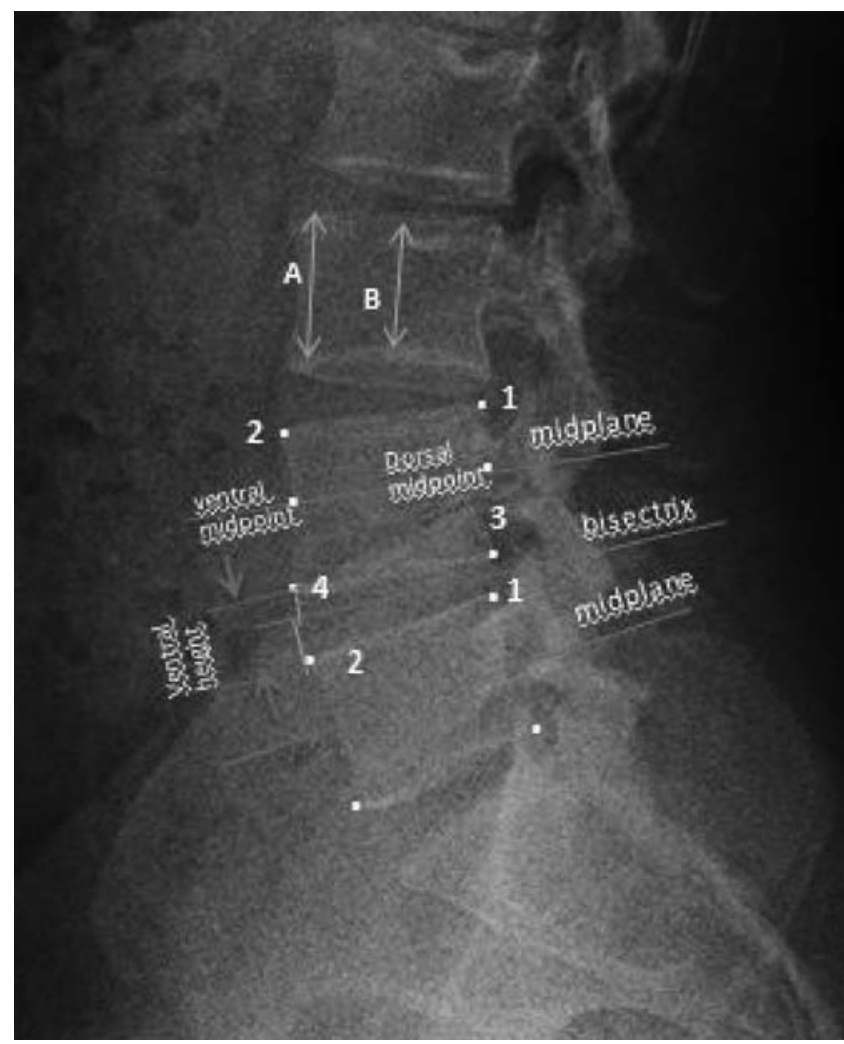

Figure 1. Schematic representation of measurements of ventral intervertebral disc height and concavity index (B/A) on lateral radiography. 


\section{Results}

Of the 150 subjects included in this study, 80 (53.3\%) were women and 70 (46.7\%), were mean; mean age was $20.83 \pm 1.80$ (range: 18 to 27 ) years. They had a mean height of $169.3 \pm 8.85$ (range: 151 to 190 ) $\mathrm{cm}$, mean body weight of $63.76 \pm 12.15$ (range: 43 to 97 ) $\mathrm{kg}$, and mean BMI of $23.30 \pm 2.73$ (range: 18.99 to 29.43 ) $\mathrm{kg} / \mathrm{m}^{2}$. The demographic characteristics of the groups are given in Table $\mathbf{1}$.

Disc height values of the groups are given in Table 2. Men presented higher lumbar disc values (T12-L1, L1-L2, L2-L3, L3-L4, L4-L5, and L5-S1) than women ( $<<0.001$ ). In both gender, disc height values increased from T12-L1 to L4-L5 and then slightly decreased at L5-S1.

Correlation coefficients and statistical evaluation of interrelation between demographics and disc height are given in Table 3. The heights of lumbar discs increased with advancing age $(\mathrm{p}<0.001)$, weight $(\mathrm{p}<0.001)$, height $\mathrm{p}<0.001)$ and BMI $(\mathrm{p}<0.001)$ in both genders. Concavity index values of the groups are given in Table 4 . Women demonstrated a higher concavity index (L2, L3 and L4 vertebrae) than men $(\mathrm{p}<0.001)$. However, men showed a higher concavity index value at L5 vertebra than women $(\mathrm{p}<0.001)$. Correlation coefficients and statistical evaluation of interrelation between demographics and concavity index are given in Table 5. The concavity index of vertebrae (T12, L1, L2, L3 and L4) decreased with advancing age $(\mathrm{p}<0.01)$. The concavity index of L2, L3 and L4 vertebrae decreased with advancing weight, height and BMI of the subjects $(\mathrm{p}<0.01)$. On the other hand, the concavity index of L5 vertebrae increased with advancing weight, height and BMI of the subjects $(\mathrm{p}<0.01)$.

\section{Discussion}

IV discs have an important role in posture, biomechanics, and balancing of the body. They show morphological and
Table 2

Disc height values of the groups using Mann-Whitney $U$ test.

\begin{tabular}{lcccc}
\hline $\begin{array}{l}\text { Disc height } \\
(\mathbf{m m})\end{array}$ & $\begin{array}{c}\text { Male } \\
(\mathbf{n}=\mathbf{7 0})\end{array}$ & $\begin{array}{c}\text { Female } \\
\mathbf{( n = 8 0 )}\end{array}$ & $\begin{array}{c}\text { Total } \\
(\mathbf{n}=\mathbf{1 5 0 )}\end{array}$ & $\mathbf{p}$ \\
\hline T12-L1 & $6.14 \pm 0.56$ & $5.16 \pm 0.37$ & $5.61 \pm 0.67$ & $\mathrm{p}<0.001$ * \\
L1-L2 & $7.97 \pm 0.61$ & $7.16 \pm 0.4$ & $7.54 \pm 0.65$ & $\mathrm{p}<0.001$ * \\
L2-L3 & $9.71 \pm 0.72$ & $9.04 \pm 0.35$ & $9.35 \pm 0.65$ & $\mathrm{p}<0.001$ * \\
L3-L4 & $11.91 \pm 0.29$ & $10.43 \pm 0.52$ & $11.11 \pm 0.85$ & $\mathrm{p}<0.001$ * \\
L4-L5 & $11.98 \pm 0.33$ & $11.44 \pm 0.55$ & $11.69 \pm 0.54$ & $\mathrm{p}<0.001$ * \\
L5-S1 & $11.52 \pm 0.5$ & $10.59 \pm 0.74$ & $11.02 \pm 0.79$ & $\mathrm{p}<0.001$ * \\
\hline
\end{tabular}

${ }^{*} \mathrm{p}<0.001$

functional changes throughout life starting from birth according to the body's needs, which mostly occur due to genetic and hormonal effects in up to three decades. ${ }^{[11]}$ Therefore, we aimed to determine the segmental disc height and concavity index of the lumbar spine in a young healthy Turkish population. In determining the changes in the IV discs, disc height measurements are usually used. Previously, decreases in disc heights with age have been evaluated as pathological ${ }^{[12,13]}$ and reported mostly in men. ${ }^{[14]}$ However, subsequent studies have shown that the anterior disc height increased steadily in first five decades in both age in both genders and decreased afterwards. ${ }^{[15-17]}$ Berlemann et al., ${ }^{[6]}$ in their cadaver study, indicated that degenerative changes due to aging might reduce disc height. On the other hand, Twomey and Taylor ${ }^{[18]}$ reported in their radiographic study on people aged 20-35 years and over 60 years that there was a clear upward trend in disc heights with increasing age. Moreover, in succeeding studies, the lumber discs of participants in each decade showed gradual increase from L1-L2 to L5-S1 in the craniocaudal direction. ${ }^{[10,19-21]}$ In other studies, it was reported that with aging, the disc height increase in each segment was $10 \% \cdot{ }^{[14,22]}$ The present study demonstrated lumbar disc

Table 3

Correlations between demographics and disc height using Spearman's correlation coefficient.

\begin{tabular}{|c|c|c|c|c|c|c|c|c|}
\hline & \multicolumn{2}{|c|}{ Age } & \multicolumn{2}{|c|}{ Weight } & \multicolumn{2}{|c|}{ Height } & \multicolumn{2}{|c|}{ BMI } \\
\hline & $r$ & $\mathbf{p}$ & $r$ & p & $r$ & $p$ & $r$ & $p$ \\
\hline T12-L1 & 0.505 & $\mathrm{p}<0.001$ * & 0.649 & $\mathrm{p}<0.001$ * & 0.679 & $\mathrm{p}<0.001$ * & 0.385 & $\mathrm{p}<0.001$ * \\
\hline L1-L2 & 0.566 & $p<0.001 *$ & 0.556 & $\mathrm{p}<0.001$ * & 0.56 & $p<0.001$ * & 0.317 & $p<0.001$ * \\
\hline L2-L3 & 0.422 & $\mathrm{p}<0.001$ * & 0.477 & $\mathrm{p}<0.001$ * & 0.5 & $\mathrm{p}<0.001$ * & 0.18 & $\mathrm{p}<0.001$ * \\
\hline L3-L4 & 0.38 & $p<0.001 *$ & 0.705 & $\mathrm{p}<0.001$ * & 0.741 & $p<0.001$ * & 0.431 & $\mathrm{p}<0.001^{*}$ \\
\hline L4-L5 & 0.552 & $\mathrm{p}<0.001$ * & 0.456 & $\mathrm{p}<0.001$ * & 0.407 & $\mathrm{p}<0.001^{*}$ & 0.336 & $\mathrm{p}<0.001 *$ \\
\hline L5-S1 & 0.634 & $\mathrm{p}<0.001$ * & 0.554 & $\mathrm{p}<0.001$ * & 0.520 & $\mathrm{p}<0.001^{*}$ & 0.393 & $\mathrm{p}<0.001$ * \\
\hline
\end{tabular}

${ }^{\star} p<0.001$ 
height increased in the craniocaudal direction from T12-Ll to L4-L5 with age in both genders, which was more significant in men. L4-L5 disc height was also greater compared to L5-S1 disc height. Kapakin and $\mathrm{Akşit}^{[23]}$ and Malkoç et al. ${ }^{[2]]}$ in their MR studies, reported increase in lumbar disc height with age, as well as in craniocaudal direction for each decade depending on age in both genders. Disk heights of the participants in third decade of life were examined. Kapakin and Akşit ${ }^{[23]}$ measured the L4-L5 level as $11.9 \mathrm{~mm}$ for both genders, and the L5-S1 level as $12.8 \mathrm{~mm}$ for men and $12.7 \mathrm{~mm}$ for women.

Furthermore, Malkoç et al. ${ }^{[2]]}$ measured mean disc heights at the L4-L5 level as $14.3 \mathrm{~mm}$ in men and 13.6 $\mathrm{mm}$ in women, and the L5-S1 level as $13.92 \mathrm{~mm}$ for men and $14.45 \mathrm{~mm}$ for women. In another study, Berlemann et al. ${ }^{[6]}$ evaluated 13 L4-L5 and 10 L5-S1 level intervertebral discs of cadavers under the age of 40 , with no history of lumbar region disorders. They measured the mean height of the discs as $12.7 \mathrm{~mm}$ in both L4-5 and L5-S1 levels. In our study, referring to measurements on radiographic examination of healthy adults, mean heights were measured for L4-L5 $11.98 \mathrm{~mm}$ and L5-S1 $11.52 \mathrm{~mm}$ in men while L4-L5 $11.44 \mathrm{~mm}$ and L5-S1 $10.59 \mathrm{~mm}$ in women. The decrease in disc height at L5-S1, which was determined in the present study, was consistent with the results of Humzah and Soames. ${ }^{[1]]}$ There are also different studies reporting a decrease in disc height at the L5-S1 level. Various studies, in which study populations consisted of obese individuals, heavy-duty workers or professional athletes, found a decrease in L5-S1 disc height as well. ${ }^{[2-26]}$ This difference in the L5-S1 level may be due to the shape of the disc, its connection with the sacrum, involvement of the lordosis angle to the formation and rupture of the annulus fibrosis due to the disruption of the superior and inferior endplate as a result of great axial forces (loads) affecting the discs related to performing heavy duties or
Table 4

Concavity index values of the groups using Mann-Whitney $\mathrm{U}$ test.

\begin{tabular}{lcccc}
\hline & $\begin{array}{c}\text { Male } \\
(\mathbf{n}=\mathbf{7 0})\end{array}$ & $\begin{array}{c}\text { Female } \\
(\mathbf{n}=\mathbf{8 0})\end{array}$ & $\begin{array}{c}\text { Total } \\
(\mathbf{n}=\mathbf{1 5 0 )}\end{array}$ & $\mathbf{p}$ \\
\hline $\mathrm{T} 12$ & $0.9855 \pm 0.01$ & $0.9861 \pm 0.01$ & $0.9859 \pm 0.01$ & 0.879 \\
$\mathrm{~L} 1$ & $0.9806 \pm 0.01$ & $0.9796 \pm 0.01$ & $0.9801 \pm 0.01$ & 0.342 \\
$\mathrm{~L} 2$ & $0.9614 \pm 0.01$ & $0.9673 \pm 0.01$ & $0.9646 \pm 0.01$ & $\mathrm{p}<0.001$ * \\
L3 & $0.9546 \pm 0.02$ & $0.962 \pm 0.01$ & $0.9586 \pm 0.01$ & $\mathrm{p}<0.001$ * \\
L4 & $0.9408 \pm 0.02$ & $0.9636 \pm 0.01$ & $0.953 \pm 0.02$ & $\mathrm{p}<0.001$ * \\
L5 & $0.886 \pm 0.02$ & $0.868 \pm 0.01$ & $0.8764 \pm 0.02$ & $\mathrm{p}<0.001$ * \\
\hline
\end{tabular}

${ }^{*} \mathrm{p}<0.001$

heavy sports activities. ${ }^{[27]}$ A limitation of the present study is the lack of information on profession and involvement of participants in sports activities. Another limitation is the absence of obese participants in this study which includes normal and overweight participants according to BMI.

Another parameter that was evaluated in our study was the concavity index. Concavity index is the evaluation of the changes on the surface between the disc and vertebral body due to aging. ${ }^{[10]}$ Currently, the concavity index is used for radiographic diagnosis of osteoporosis and lumbar spinal anomalies. ${ }^{[10,25,28]}$ Change in concavity index with aging is controversial because both increase and decrease in concavity index with aging were reported in the literature. ${ }^{[6,10,17,20,29]}$ The present study demonstrated decrease in concavity index with aging in both genders.

\section{Conclusion}

We observed that the disc height increased with age from T12-L1 to L4-L5 in the craniocaudal direction; in contrast, L5-S1 disc height decreased. Decrease in concavity index of lumbar vertebrae with aging was also observed. This study is a cross-sectional one, because of

Table 5

Correlations between demographics and concavity index using Spearman's correlation coefficient.

\begin{tabular}{|c|c|c|c|c|c|c|c|c|}
\hline & \multicolumn{2}{|c|}{ Age } & \multicolumn{2}{|c|}{ Weight } & \multicolumn{2}{|c|}{ Height } & \multicolumn{2}{|c|}{ BMI } \\
\hline & $r$ & p & $r$ & $p$ & $r$ & $p$ & $r$ & $p$ \\
\hline $\mathrm{T} 12$ & -0.362 & $p<0.001 *$ & -0.112 & 0.189 & -0.052 & 0.389 & -0.087 & 0.308 \\
\hline L1 & -0.431 & $\mathrm{p}<0.001 *$ & -0.052 & 0.545 & 0.034 & 0.774 & -0.09 & 0.291 \\
\hline L2 & -0.529 & $p<0.001 *$ & -0.385 & $p<0.001 *$ & -0.326 & $p<0.001$ * & -0.233 & 0.006 \\
\hline L3 & -0.469 & $p<0.001^{*}$ & -0.329 & $p<0.001^{*}$ & -0.220 & $0.009^{*}$ & -0.171 & 0.043 \\
\hline L4 & -0.339 & $p<0.001$ * & -0.647 & $p<0.001^{*}$ & -0.633 & $p<0.001$ * & -0.254 & 0.002 \\
\hline L5 & -0.147 & 0.162 & 0.479 & $p<0.001^{*}$ & 0.580 & $p<0.001^{*}$ & 0.255 & 0.002 \\
\hline
\end{tabular}

${ }^{*} p<0.05$ 
this, the results cannot be applied to the whole of this age group population. However, these results will serve as guidelines for radiological evaluation of lumbar spine in young healthy adults.

\section{References}

1. Junghanns H. Die gesunde und die kranke wirbelsäule in röntgenbild und klinik. Stuttgart: Georg Thieme Verlag; 1968.

2. DePalma MJ, Ketchum JM, Saullo T. What is the source of chronic low back pain and does age play a role? Pain Med 2011;12:224-33.

3. Ghannam M, Jumah F, Mansour S, Samara A, Alkhdour S, Alzuabi MA, Aker L, Adeeb N, Massengale J, Oskouian RJ, Tubbs RS Surgical anatomy, radiological features, and molecular biology of the lumbar intervertebral discs. Clin Anat 2017;30:251-66.

4. Choi YS. Pathophysiology of degenerative disc disease. Asian Spine J 2009;3:39-44.

5. Budak EÇ, Bozkurt MR. Vertebra lomber disklerde meydana gelen bozulmaların manyetik rezonans görüntüleme (MRG) ile analizi. Online Academic Journal of Information Technology 2013;4:125-44.

6. Berlemann U, Gries NC, Moore RJ. The relationship between height, shape and histological changes in early degeneration of the lower lumbar discs. Eur Spine J 1998;7:212-7.

7. Kutsal YG, İnanıcı F, Oğuz KK, Alanay A, Palaoğlu S. Bel ağrıları. Hacettepe Tip Dergisi 2008;39:180-93.

8. Şenköylü A. Bel ağrısında kırmızı bayraklar. Türkiye Fiziksel Tıp ve Rehabilitasyon Dergisi 2011;57 (Özel Sayı 2).

9. Leivseth G, Salvesen R, Hemminghytt S, Brinckmann P, Frobin W. Do human lumbar discs reconstitute after chemonucleolysis? A 7year follow-up study. Spine (Phila Pa 1976) 1999;24:342-7.

10. Shao Z, Rompe G, Schiltenwolf M. Radiographic changes in the lumbar intervertebral discs and lumbar vertebrae with age. Spine (Phila Pa 1976) 2002;27:263-8.

11. Humzah MD, Soames RW. Human intervertebral disc: structure and function. Anat Rec 1988;220:337-56.

12. Lawrence JS. Disc degeneration, its frequency and relationship to symptoms. Ann Rheum Dis 1969;28:121-38.

13. Schmorl G, Junghanns H. The human spine in health and disease. 2nd ed. New York: Grune \& Stratton; 1971. p. 18.

14. Vernon-Roberts B, Pirie CJ. Degenerative changes in the intervertebral discs of the lumbar spine and their sequelae. Rheumatol Rehabil 1977;16:13-21.

15. Amonoo-Kuofi HS. Morphometric changes in the heights and anteroposterior diameters of the lumbar intervertebral discs with age. J Anat 1991;175;159-68.
16. Al-Hadidi MT, Badran DH, Al-Hadidi AM, Abu-Ghaida JH. Magnetic resonance imaging of normal lumbar intervertebral discs. Saudi Med J 2001;22:1013-8.

17. Sevinc O, Barut C, Eryoruk N, Safak AA. Influence of age and sex on lumbar vertebral morphometry determined using sagittal magnetic resonance imaging. Ann Anat 2008;190:277-83.

18. Twomey L, Taylor J. Age changes in lumbar intervertebral discs. Acta Orthop Scand 1985;56:496-9.

19. Pfirrmann CW, Metzdorf A, Elfering A, Hodler J, Boos N. Effect of aging and degeneration on disc volume and shape: a quantitative study in asymptomatic volunteers. J Orthop Res 2006;24:1086-94.

20. Gocmen-Mas N, Karabekir H, Ertekin T, Edizer M, Canan Y, Duyar I. Evaluation of lumbar vertebral body and disc: a stereological morphometric study. Int J Morphol 2010; 28:841-7.

21. Malkoç I, Aydinlioglu SA, Alper F, Kaciroglu F, Yuksel Y, Yuksel R, Dane S, Toktas M. Age related changes in height and shape of the lumbar intervertebral discus. Europoean Journal of Basic Medical Sciences 2012;2:68-73.

22. Bogduk N. Klinische Anatomie von Lendenwirbelsäule und Sakrum. Berlin: Springer Verlag; 2000.

23. Kapakin S, Akşit D. Manyetik rezonans görüntüleme yöntemi ile lumbal intervertebral disklerin morfometrik değerlendirilmesi. Atatürk Üniversitesi Veteriner Bilimleri Dergisi 2009;4:2:77-85.

24. Urquhart DM, Kurniadi I, Triangto K, Wang Y, Wluka AE, O'Sullivan R, Jones G, Cicuttini FM. Obesity is associated with reduced disc height in the lumbar spine but not at the lumbosacral junction. Spine (Phila Pa 1976) 2014;39:E962-6.

25. Öztürk A, Özkan Y, Özdemir RM, Yalçin N, Akgöz S, Saraç V, Aykut S. Radiographic changes in the lumbar spine in former professional football players: a comparative and matched controlled study. Eur Spine J 2008;17:136-41.

26. Schmitt H, Dubljanin E, Schneider S, Schiltenwolf M. Degenerative changes in the lumbar spine in former elite athletes. Spine (Phila Pa 1976) 2004;29:2554-9.

27. Bogduk N. Functional anatomy of the disc and the lumbar spine. Janz KB, Hochschuler SH, McAfee PC, editors. The artificial disc. Heidelberg: Springer Verlag; 2003. pp. 19-32.

28. Souza FR, Ferreira F, Narciso FV, Makhoul CMB, Canto RST, Barauna MA. Evaluation of lumbar concavity using a radiographic method and kypholordometry. Revista Brasileara Fisioterapia 2009;13:103-9.

29. Ismail AA, Cooper C, Felsenberg D, Varlow J, Kanis JA, Silman AJ, O'Neill TW. Number and type of vertebral deformities: epidemiological characteristics and relation to back pain and height loss. The European Vertebral Osteoporosis Study. Osteoporos Int 1999;9: 206-13.

This is an open access article distributed under the terms of the Creative Commons Attribution-NonCommercial-NoDerivs 3.0 Unported (CC BY-NCND3.0) Licence (http://creativecommons.org/licenses/by-nc-nd/3.0/) which permits unrestricted noncommercial use, distribution, and reproduction in any medium, provided the original work is properly cited. Please cite this article as: Demir M, Atay E, Seringeç N, Yoldaş A, Çiçek M, Ertoğrul R, Güneri B. Intervertebral disc heights and concavity index of the lumbar spine in young healthy adults. Anatomy 2018;12(1):33-37. 